\title{
Money attitude, self-esteem, and compulsive buying in a population of medical students
}

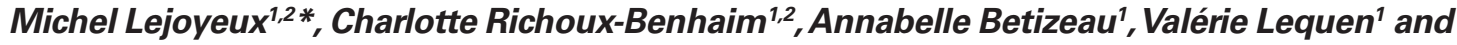 Hannah Lohnhardt ${ }^{1}$}

1 Department of Psychiatry, Assistance Publique-Hôpitaux de Paris, Hospital Bichat-Claude Bernard, Paris, France

2 Department of Psychiatry, Hospital Maison Blanche, Paris, France

Edited by:

Alain Dervaux, Centre Hospitalier

Sainte-Anne, France

Reviewed by:

Laurent Karila, Université Paris Sud, France

Aviv Weinstein, Hebrew University Hospital, Israel

\section{*Correspondence:}

Michel Lejoyeux, Department of

Psychiatry, Assistance Publique-

Hôpitaux de Paris, Hospital Bichat-

Claude Bernard, 75877 Paris Cedex 18,

France.

e-mail:michel.lejoyeux@bch.aphp.fr
This study tried to determine the prevalence of compulsive buying (CB) and to identify among compulsive buyers a specific relation to money, a different buying style, and a lowered level of self-esteem. We included 203 medical students and diagnosed CB with the Mc Elroy criteria and a specific questionnaire. The money attitude was characterized by the Yamauchi and Templer's scale and self-esteem with the Rosenberg scale. $11 \%$ of the medical students presented compulsive buying $(\mathrm{CB}+)$. Sex ratio and mean ages were comparable in the $\mathrm{CB}+$ and control groups. $\mathrm{CB}+$ students drank less alcohol and smoked an equivalent number of cigarettes. Compulsive buyers had higher scores of distress (tendency to be hesitant, suspicious, and doubtful attitude toward situations involving money) and bargain missing (fear of missing a good opportunity to buy an item). They bought more often gifts for themselves, items they use less than expected and choose goods increasing their self-esteem. Their score of self-esteem was not different from the one from controls.

Keywords: compulsive buying, addiction, self-esteem, money

\section{INTRODUCTION}

Compulsive buying $(\mathrm{CB})$ corresponds to repetitive, uncontrolled urges to buy items which are not needed. Buying sprees induce financial difficulties, reproaches, and conflicts with family (Lejoyeux et al., 1996). Mc Elroy et al. (1994) proposed diagnostic criteria for CB patterned after DSM-IV-R criteria for obsessive compulsive, impulse control, and substance abuse disorders. They excluded buying sprees from manic patients which are related to euphoria, hyperactivity, grandiosity, and poor judgment. According to Mc Elroy et al. (1994), compulsive buyers experience mounting tension which may only be relieved by buying. The tension temporarily assuaged by a purchase is quickly replaced by guilt, sadness, and self-reproach.

Compulsive buying can be included in the "addictive spectrum" due to its clinical characteristics in common with classical addictive disorders, i.e., failure to resist an impulse, drive or temptation to perform some act harmful to oneself and/or to others, increasing sense of tension or excitement before acting out; loss of control, sense of pleasure, gratification, or release at the time of buying or shortly thereafter. In addition, CB is often associated with "classical" dependence on alcohol and nicotine (Lejoyeux et al., 1997). Among a population of $500 \mathrm{female}$ patients consulting their general practitioner, CB was present in 97 cases (38\%) and more frequent among patients with nicotine dependence (58 cases, $45 \%$ ) than among those who were not dependent on nicotine (39 cases, $31 \%$; Lejoyeux et al., 2006).

Compulsive buyers have a specific relation to money and items bought during their buying sprees. Compulsive buyers decide more often to buy during their visit in the shop and consider more often their purchases as opportunities not to be passed. They buy items more often to impress others and tend to consider their purchases as personally gratifying. Designer's brands induce for them a greater motivation to buy (Lejoyeux et al., 2007). d'Astous (1990) also found that compulsive buyers are more likely to consider buying as an expression of a high social status. Elliot (1994) noted that one of the primary functions of $\mathrm{CB}$ is to increase the compulsive buyer's ability to match his or her subjective perception of socially desirable appearance. However, "status consumption" (Roberts and Jones, 2001) requires consumers to continually increase their conspicuous signals of wealth and power. Lastly, compulsive buyers are regularly deceived by items they buy. They use them less than expected, try to give them back to shops and sometimes hide them or throw them away (Lejoyeux et al., 1996).

Compulsive buying is often associated with depression and/or low self-esteem. Specific studies found (Lejoyeux et al., 1996) a prevalence rate of $31.9 \%$ for $\mathrm{CB}$ among individuals hospitalized for depression. According to Miltenberger et al. (2003), when compulsive buyers are asked to describe how they feel before a typical buying episode, $53 \%$ say they are sad or depressed and $21 \%$ tense or anxious. When asked about their feeling after a buying episode, $42 \%$ say they feel guilty and $21 \%$ sad or depressed. Compulsive buyers are more likely to engage in their pathological behavior when they experience negative emotions. They obtain a temporary relief from their negative emotions and decreased self-esteem. A positive and significant relationship was also found between anxiety and CB (Roberts and Jones, 2001). Compulsive buyers use the shopping activity as a means of relieving stress and low self-esteem. No study specifically tested the association between $\mathrm{CB}$, attitude toward money and self-esteem. The objective of the present work was thus to compare these parameters between compulsive buyers and non-compulsive buyers. 


\section{MATERIALS AND METHODS}

The study was conducted in a population of medical students in which we identified "compulsive" and "normal" buyers. All data were compared between these two sub-groups of students.

\section{SUBJECTS}

We administered our questionnaires to a sample of medical students of the Paris 7 University, during two months (April and May 2010). The sample consisted of 134 women and 69 men. We included students from all years. To ensure confidentiality, we did not record any identifying data. Questionnaires were strictly anonymous. All students participated voluntarily in the study. Written informed consent was obtained from everyone after an explanation of the study. Before beginning the study, we tested the validity and the reliability of all questionnaires in 20 subjects. All parts of the questionnaire consisted of scales previously validated (Achour et al., 2004). All interviews were personally conducted by the same investigator (Hannah Lohnhardt). For those who completed it, the assessment took approximately $15 \mathrm{~min}$.

\section{ASSESSMENTS}

\section{Socio-demographic characteristics and alcohol consumption}

The questionnaire began with an assessment of age, marital status, and daily consumption of alcohol and nicotine. We used a standardized questionnaire previously validated (Achour et al., 2004) in French to quantify the number of drinks taken each day. A drink was defined as the amount of alcohol found in $300 \mathrm{ml}$ of beer, $100 \mathrm{ml}$ of wine, or $25 \mathrm{ml}$ of whisky. We also noted the number of days per week in which drinking had occurred during the last month. Lastly, the number of cigarettes smoked each day was counted.

\section{Diagnosis of compulsive buying}

We used two different assessments of CB. We checked a French version of the Mc Elroy et al. (1994) criteria for CB and all subjects answered the Questionnaire about Buying Behaviour (QABB; Lejoyeux et al., 1997). This questionnaire, originally written in French, consists of 19 yes-no items representing major basic features of $\mathrm{CB}$ (e.g., urges to shop and buy, negative feedback from family and friends, post-purchase guilt) based on the Mc Elroy et al. (1994) criteria. The QABB is self-administered. Subjects with a score greater than nine are considered as compulsive buyers.

All subjects included in the "compulsive buying group" (CB+) met the Mc Elroy et al.'s criteria and scored more than 9 at the QABB. They presented repetitive and impulsive buying behavior, euphoria, or excitement before purchase, post-purchase guilt, and real negative consequences of their behavior. In all cases, CB caused to them significant financial hardship.

\section{Money attitude}

The Yamauchi and Templer's (1982) 29-items Money Attitude Scale (MAS) identifies five factors describing the relation to money. Power-Prestige, is a tendency to use money to influence and impress others. Retention Time assesses tendency to careful financial planning and Distrust represents hesitant, suspicious, and doubtful attitude toward situations involving money. Anxiety measures to what extent money can be seen as a source of anxiety and Affair missing reflects fear of missing a good opportunity to buy an item. Yamauchi and Templer's (1982) scale has been used across ethnically diverse samples and has shown a stable factor structure and acceptable Cronbach's alpha for each of its subscales (Roberts and Sepulveda, 1999). We translated the questionnaire in French, made a back translation, and used the version obtained after the back translation.

\section{"Buying style"}

We characterized the buying style with another specific questionnaire previously validated in French (Lejoyeux et al., 2007) allowing the rating of the following buying patterns:

\section{Gifts for oneself}

Buying during sales periods

Purchases considered as exceptional

Purchases as occasions not to be missed

Purchases followed by deception

Items less used than expected

Purchases made to impress others

Buying increasing self-esteem

\section{Self-esteem}

The Rosenberg (1965) self-esteem scale is a widely used selfesteem measure consisting in a 10-item Likert scale with items answered on a 4-point scale from strongly agree (rated 3) to strongly disagree (rated 0 ). The scores range from 0 to 30 . Scores between 15 and 25 are within normal range; scores below 15 suggest low self-esteem. The self-esteem scale has been translated and validated in French (Vallieres and Vallerand, 1990). We used this French version.

\section{Statistics}

For each variable, we compared subjects presenting or not CB. We made comparisons for continuous variables using unpaired two-tailed Student's $t$ tests. For categorical data, differences in proportions were compared with the $\chi^{2}$-test. Correlation between quantitative variable were made with Pearson's test. Statistical significance was determined at the 0.05 level of confidence.

\section{RESULTS}

A total of 203 students were included. Prevalence of CB was $11 \%$ (23 subjects). Five students refused the questionnaire due to a lack of time to complete the study. None of the students were followed by a psychiatrist or a psychologist and none of them had been hospitalized in psychiatry.

\section{SOCIO-DEMOGRAPHIC CHARACTERISTICS, ALCOHOL AND NICOTINE CONSUMPTION, AND SELF-ESTEEM}

There was no statistical difference between the characteristics of students with and without $\mathrm{CB}$ in regard to age, sex, and marital status. Compulsive buyers drank significantly less ( 1 versus 2 drinks per day) than controls $(t=2.1, \mathrm{df}=202, p=0.03)$. Their number of drinking days per week was however equivalent. Compulsive buyers smoked each day a number of cigarettes equivalent to those smoked by controls. Self-esteem mean scores, as assessed with the Rosenberg scale, were not different between the two groups (Table 1). 


\section{SCORES OF COMPULSIVE BUYING AND MONEY ATTITUDE}

Mean scores at the QABB compulsive buying scale were significantly higher in the $\mathrm{CB}+$ group $(9.3$ versus $3.9, t=12.4, p<0.001)$. The MAS scores were higher in the $\mathrm{CB}+$ group for two subscales: Distrust and Bargain missing. Correlation studies (Pearson test) showed that CB mean scores are significantly $(p<0.05)$ correlated to three subscales of the MAS, i.e., scores of Distrust $(r=0.23)$, Anxiety $(r=0.14)$, and Affair missing $(r=0.35$; Table 1).

\section{RELATION TO ITEMS BOUGHT}

Students presenting CB made more often self-gifts (25 versus $21 \%$ in the CB- group). They did not buy more often during bargain periods and did not consider more often their purchases as exceptional or as occasions not to be missed. Percentage of purchases less used than expected was higher in the CB+ group (24 versus $19 \%$ in the CB- group). Purchases from compulsive buyers more often increased their level of self-esteem ( 28 versus 24\%; Table 2).

\section{DISCUSSION}

Our study has several limitations reducing the impact of its results. First, the number of subjects studied is relatively small and data concerning CB only rely on 23 subjects. Another limitation is that all subjects included are medical students from the same university. They are not representative of all categories of buyers from the general population. We have chosen to assess medical students because they are young subjects who have a regular activity at the university and at the hospital and who earn money. All of them were between their third and sixth year in the medical university. Comparison with data drawn from other studies conducted in specialized consultations or among psychiatric patients must thus be cautious. This study, however, is the only one which assessed simultaneously, in a sample of young adults enrolled in education and who were not psychiatric subjects, $\mathrm{CB}$, money attitude, buying style, and self-esteem. We only used questionnaires previously validated in French and we translated the MAS.

Table 1 | Comparison of students presenting with (CB+) or without (CB-) compulsive buying.

\begin{tabular}{|c|c|c|c|c|c|c|}
\hline & $\begin{array}{l}\mathrm{CB}+(N=23,11 \%) \\
\%(M)\end{array}$ & \multicolumn{2}{|c|}{$\begin{array}{l}\mathrm{CB}-(N=180,89 \%) \\
\%(M)\end{array}$} & $\begin{array}{l}\text { All subjects }(N=203) \\
\%(N)\end{array}$ & \multicolumn{2}{|c|}{ Statistics } \\
\hline \multirow[t]{2}{*}{ Married or living in couple } & $78(18)$ & & & $64(130)$ & 2.2 & 1 \\
\hline & Mean (SD) & Mean (SD) & Mean (SD) & $\boldsymbol{t}$ & df & $p$ \\
\hline Alcohol drinks per day & $1(1.4)$ & $2(2.1)$ & $1.9(4.4)$ & 2.1 & 202 & 0.03 \\
\hline Days per week with alcohol & $1.2(1.7)$ & $1.5(1.6)$ & $1.5(1.6)$ & -0.9 & 202 & \\
\hline Cigarettes per day & $2.4(4.2)$ & $3.2(6.2)$ & $3.1(1.8)$ & -0.59 & 202 & \\
\hline Self-esteem score & $26(2.6)$ & $27(2.8)$ & $27(2.8)$ & -1.7 & 202 & \\
\hline Scores of buying scale & $9.3(1.3)$ & $3.9(4)$ & $4.5(6.7)$ & 12.4 & 202 & $<0.001$ \\
\hline Anxiety & $7.4(4.7)$ & $7.1(4.3)$ & $7.1(4.3)$ & 0.34 & 202 & \\
\hline Affair missing & $7.5(3.6)$ & $4.7(3)$ & 5 (3.3) & 3.8 & 202 & $<0.001$ \\
\hline
\end{tabular}

Bold values are statistically significant

Table 2 | Comparison of subjects presenting with (CB+) or without (CB-) compulsive buying.

\begin{tabular}{|c|c|c|c|c|c|c|}
\hline & \multirow{2}{*}{$\begin{array}{l}\mathrm{CB}+(N=23,11 \%) \\
\text { Mean (SD) }\end{array}$} & \multirow{2}{*}{$\begin{array}{l}\text { CB- }(N=180,89 \%) \\
\text { Mean (SD) }\end{array}$} & \multirow{2}{*}{$\begin{array}{l}\text { All subjects }(N=203) \\
\text { Mean (SD) }\end{array}$} & \multicolumn{3}{|c|}{ Statistics } \\
\hline & & & & $t$ & df & $\boldsymbol{p}$ \\
\hline$\%$ of self-intended gifts & $49(25)$ & $40(21)$ & $41(21)$ & 2 & 202 & 0.04 \\
\hline$\%$ of purchases during sales periods & $39(22)$ & $34(25)$ & $35(24)$ & 0.845 & 202 & \\
\hline$\%$ of purchases considered as exceptional & $35(24)$ & $28(21)$ & $29(21)$ & 1.4 & 202 & \\
\hline$\%$ of purchases considered as occasions & $34(24)$ & $26(21)$ & $27(22)$ & 1.6 & 202 & \\
\hline \multicolumn{7}{|l|}{ not to be missed } \\
\hline$\%$ of purchases followed by deception & $19(19)$ & $14(12)$ & $15(13)$ & 1.6 & 202 & \\
\hline$\%$ of purchases less used than expected & $36(24)$ & $22(19)$ & $24(20)$ & 3.2 & 202 & $<0.001$ \\
\hline$\%$ of purchases made to impress others & $9(13)$ & $7(10)$ & $7(11)$ & 0.9 & 202 & \\
\hline$\%$ of purchases increasing self-esteem & $40(28)$ & $29(24)$ & $31(25)$ & 1.9 & 202 & 0.05 \\
\hline
\end{tabular}

Bold values are statistically significant 
Prevalence rate of CB was $11 \%$ in our population. This rate is higher than those previously reported. Dittmar and Drury (2000) suggested that, in economically developed countries, $2-5 \%$ of the population buy compulsively. Faber and O'Guinn (1992) found a prevalence of $1.1 \%$ in the general population. Koran et al. (2006) interviewed 2513 adults in a random telephone survey and estimated prevalence rate of CB in the USA at 5.8\%. The only study which found a higher prevalence rate for CB was Kukar-Kinney et al. (2009) work. The authors identified $17.7 \%$ of compulsive buyers among 1490 customers of an Internet women's clothing retailer. This group of "modern" compulsive buyers was addicted to "cybershopping." Medical students differ from customers of Internet women's clothing retailer group. Subjects from the KukarKinney et al.'s (2009) study are dedicated to buying clothes whereas medical students represent a more general group of the population. All medical students however possess a personal computer at home and can also connect themselves to the web during their stay at the university. Another explanation could be that CB is a growing phenomenon and that more recent studies find higher prevalence rates than older studies. The lack of difference between men and women in our study may once again indicate the appearance of a new type of $\mathrm{CB}$ as prevalent in men as in women, in a population of young people using Internet more regularly.

We failed to show an association between CB and alcohol and nicotine consumption. Compulsive buyers drank significantly less than non-buyers. It seems that for them alcohol is not a form of stress relief. In all cases, however, alcohol consumption remained moderate and we found no case of consumption of more than three drinks per day. Nicotine consumption was not different between compulsive buyers and controls.

The MAS identifies different factors (Roberts and Sepulveda, 1999) of buying behavior. The Power-Prestige dimension was the first to emerge in all students. To many people, money means power. Money is not used so much to purchase cars, clothes, houses, or food as it is to buy social status and feeling of domination. Consumers with a high level of Power-Prestige consider that wealth is the best indicator of power in modern society. They estimate their status more through their ownership of products than through personal, occupational, or family reputation. Nine items contribute to this factor, all of them suggesting that money could be used as a tool of power. Persons scoring high on this factor use money as a tool to influence and impress others. Scores of Power-Prestige were not higher among compulsive buyers compared to controls.

Seven items load on the second factor labeled Retention Time. These items focus on financial planning and careful use of money. Persons scoring high on this factor plan for their financial future and closely monitor their financial situation. Unsurprisingly, compulsive buyers do not have higher scores on this item. Their purchases are often impulsive and unplanned. The third factor of the MAS scale is Distrust. Yamauchi and Templer (1982) described persons scoring high on this factor as hesitant, suspicious, and doubtful regarding situations involving money. They suggested that high scores on Distrust reflect a lack of faith in one's ability to make efficient purchase decisions. Compulsive buyers show significantly higher scores of Distrust than controls. It has been previously shown that compulsive buyers return items purchased significantly more often than controls (Lejoyeux et al., 2007). Once a purchase is completed, they are more anxious and they more often regret their choice. The MAS confirms the fact that they are hesitant about choosing an item and more often disappointed by what they buy. This Distrust dimension could explain why they use items bought less than expected.

A fourth factor of the MAS scale is Anxiety. Persons scoring high on this factor may see money as a source of anxiety as well as a source of protection from anxiety. Two items of the Anxiety factor address the difficulty of having to pass up bargains or sales. Lastly, compulsive buyers present significant higher levels of Affair missing, the anxiety to miss a good opportunity to buy. They consider their purchases as occasions not to be passed up and they regret if they miss an opportunity to buy an item. This result is corroborated with clinical practice: many compulsive buyers enjoy the process of returning items back even more than the buying itself. This last point could be further investigated in another study.

In addition to the MAS questionnaire, we asked questions about the relation to items. Compulsive buyers have a stronger tendency to buy self-intended gifts. The "compensatory" dimension of purchase could be corroborated by the fact that compulsive buyers more often buy items to make gifts to themselves. In addition, they tend to buy items increasing their self-esteem. Since they are more attached to buying itself than to use or possession of items, they are often deceived by their purchases. Additional questions confirmed a specific characteristic of CB: items are used less than expected. The statistical differences between compulsive buyers and non-compulsive buyers with regard to purchasing gifts for itself, using purchases less often than expected and experiencing more often increased self-esteem after a purchase are however small in magnitude and not statistically significant. In addition, the proportion of variance accounted for by the CB scores, as indicated by the correlation to sub-scores of the MAS, are quite small, in no case more than $10 \%$.

The last assessment proposed was the level of self-esteem. Scores at the Rosenberg scale did not discriminate compulsive buyers from controls. Surprisingly compulsive buyers did not show lower baseline scores of self-esteem. Previous studies demonstrating an association between depression and CB had been conducted in psychiatric in or outpatients (Lejoyeux et al., 1997). In our non-clinical population, $\mathrm{CB}$ is not correlated to a decreased self-esteem. Questions on the buying style, however, distinguish compulsive buyers from controls, suggesting that items chosen compulsively are more often self-gifts and items which could increase self-esteem. It can be suggested that compulsive buyers have not a lower "basic" level of self-esteem. Their level of selfesteem is, however, more sensitive to the effects of their purchases and their purchases are more often decided in the hope to restore their self-esteem.

Compulsive buying is thus a frequent impulse control disorder among our sample of French medical students (11\%). Compulsive buyers have a specific relation to money characterized by a higher level of two sub-scores of the French version of the MAS: Distress (tendency to be hesitant, suspicious, and doubtful attitude toward situations involving money) and Affair missing (fear of missing a good opportunity to buy an item). They have a stronger tendency to buy self-gifts, items they use less than expected and choose goods increasing their self-esteem. 


\section{REFERENCES}

Achour, F., Brun, P., Mc Loughlin, M., Adès, J., and Lejoyeux, M. (2004). Lifestyle characteristics of patients admitted to a French medical emergency service. Alcohol Res. 94, 167-170.

d'Astous, A. (1990). An inquiry into the compulsive side of 'normal' consumers. J. Consum. Policy 13, 15-31.

Dittmar, H., and Drury, J. (2000). Self image: is it in the bag? A qualitative comparison between ordinary and excessive consumers. J. Econ. Psychol. 21, 109-142.

Elliot, R. (1994). Addictive consumption: function and fragmentation in postmodemity. J. Consum. Policy 17, 159-179.

Faber, R. J., and O'Guinn, T. C. (1992). A clinical screener for compulsive buying. J. Consum. Res. 9, 459-469.

Koran, L. M., Faber, R. J., Aboujaoude, M. A., Large, M. D., and Serpe, R. T. (2006). Estimated prevalence of compulsive buying behavior in the United States. Am. J. Psychiatry 163, 1806-1812.
Kukar-Kinney, M., Ridgway, N. M., and Monroe, K. B. (2009). The relationship between consumers' tendencies to buy compulsively and their motivation to shop and buy on the Internet. J. Retail. 85, 298-307.

Lejoyeux, M., Adès, J., Tassain, V., and Solomon, J. (1996). Phenomenology and psychopathology of uncontrolled buying. Am. J. Psychiatry 155, 1524-1529.

Lejoyeux, M., Kerner, L., Thauvin, I., and Loi, S. (2006). Study of impulse control disorders among women presenting nicotine dependence. Int. J. Psychiatry Clin. Pract. 10, 241-246.

Lejoyeux, M., Mathieu, K., Embouazza, H., and Huet F Lequen, V. (2007). Prevalence of compulsive buying among consumers of a Parisian general store. Compr. Psychiatry 48, 42-46.

Lejoyeux, M., Tassain, V., Solomon, J., and Adès, J. (1997). Study of compulsive buying in depressed patients. J. Clin. Psychiatry 58, 169-173.

Mc Elroy, S. L., Keck, P. E. Jr., Pope, H. G. Jr., Smith, J. M. R., and Strakowski, S. M. (1994). Compulsive buying: a report of 20 cases. J. Clin. Psychiatry $55,242-248$.

Miltenberger, R. G., Redlin, J., Crosby, R., Stickney, M., Mitchell, J., Wonderlich, S., and Faber R Smyth, J. (2003). Direct and retrospective assessment of factors contributing to compulsive buying. $J$. Behav. Ther. Exp. Psychiatry 34, 1-9.

Roberts, J., and Jones, E. (2001). Money attitudes, credit card use and compulsive buying among American college students. J. Consum. Aff. 35, 213-240.

Roberts, J. A., and Sepulveda, C. J. (1999). Demographics and money attitudes: a test of Yamauchi and Templer's (1982) Money Attitude Scale in Mexico. Pers. Individ. Dif. 27, 19-35.

Rosenberg, M. (1965). Society and the Adolescent Self-Image. Princeton, NJ: Princeton University Press.

Vallieres, E. F., and Vallerand, R. J. (1990). Traduction et validation canadiennefrançaise de l'Echelle de l'Estime de Soi de Rosenberg. Int. J. Psychol. 25, 305-316.

Yamauchi, K., and Templer, D. (1982). The development of a Money Attitudes Scale. J. Pers. Assess. 46, 522-528.
Conflict of Interest Statement: The authors declare that the research was conducted in the absence of any commercial or financial relationships that could be construed as a potential conflict of interest.

Received: 02 January 2011; paper pending published:04March 2011; accepted: 16March 2011; published online: 30 March 2011.

Citation: Lejoyeux M, Richoux-Benhaim $C$, Betizeau A, Lequen $V$ and Lohnhardt $H$ (2011) Money attitude, self-esteem, and compulsive buying in a population of medical students. Front. Psychiatry 2:13. doi: 10.3389/fpsyt.2011.00013

This article was submitted to Frontiers in Impulsivity, Compulsivity and Behavioral Dyscontrol, a specialty of Frontiers in Psychiatry.

Copyright (C) 2011 Lejoyeux, RichouxBenhaim, Betizeau, Lequen and Lohnhardt. This is an open-access article subject to a non-exclusive license between the authors and Frontiers Media SA, which permits use, distribution and reproduction in other forums, provided the original authors and source are credited and other Frontiers conditions are complied with. 